ARTICLE

\title{
A [6+4]-cycloaddition adduct is the biosynthetic intermediate in streptoseomycin biosynthesis
}

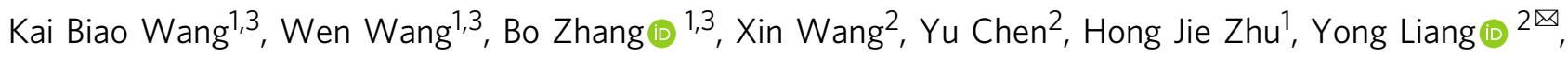
Ren Xiang Tan (1D ${ }^{1 \times} \&$ Hui Ming Ge (i) ${ }^{1 凶}$

Streptoseomycin (STM, 1) is a bacterial macrolactone that has a unique $5 / 14 / 10 / 6 / 6$ pentacyclic ring with an ether bridge. We have previously identified the biosynthetic gene cluster for 1 and characterized StmD as [6+4]- and [4+2]-bispericyclase that catalyze a reaction leading to both 6/10/6- and 10/6/6-tricyclic adducts (6 and 7). The remaining steps, especially how to install and stabilize the required 10/6/6-tricyclic core for downstream modifications, remain unknown. In this work, we have identified three oxidoreductases that fix the required 10/6/6-tryciclic core. A pair of flavin-dependent oxidoreductases, StmO1 and $\mathrm{StmO} 2$, catalyze the direct hydroxylation at [6+4]-adduct (6). Subsequently, a spontaneous [3,3]-Cope rearrangement and an enol-ketone tautomerization result in the formation of 10/6/6-tricyclic intermediate $\mathbf{1 2} \mathbf{b}$, which can be further converted to a stable 10/6/6-tricyclic alcohol $\mathbf{1 1}$ through a ketoreduction by StmK. Crystal structure of the heterodimeric complex NtfO1-NtfO2, homologues of StmO1-StmO2 with equivalent function, reveals protein-protein interactions. Our results demonstrate that the $[6+4]$ adduct instead of $[4+2]$-adduct is the bona fide biosynthetic intermediate.

\footnotetext{
${ }^{1}$ State Key Laboratory of Pharmaceutical Biotechnology, Institute of Functional Biomolecules, Chemistry and Biomedicine Innovation Center (ChemBIC), School of Life Sciences, Nanjing University, Nanjing, China. ${ }^{2}$ State Key Laboratory of Coordination Chemistry, Jiangsu Key Laboratory of Advanced Organic Materials, Chemistry and Biomedicine Innovation Center, School of Chemistry and Chemical Engineering, Nanjing University, Nanjing, China. ${ }^{3}$ These authors

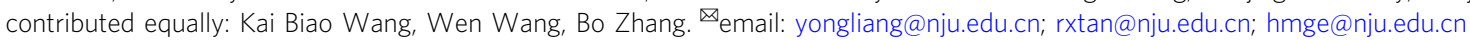


S treptoseomycin (STM, $\mathbf{1})$ is a unique bacterial macrolactone produced from a marine bacterium Streptomyces seoulensis A01 ${ }^{1}$. STM is structurally similar to nargenicin $(\mathrm{NGN}, 2)$ $\left(\right.$ Fig. 1a) ${ }^{2}$, nodusmicin ${ }^{3}$, coloradocin ${ }^{4,5}$, as well as branimycin ${ }^{6}$, all of which have a common 10(9)/6/6-tricyclic core. They are potent antibiotics against array of anaerobic or microaerophilic bacteria including the human pathogenic bacterium Helicobacter pylori, representing a class of promising antibiotics ${ }^{1-8}$. Previously, we have cloned and sequenced the biosynthetic gene clusters for $\mathbf{1}$ and 2 producers ${ }^{1,9}$. The stm and ngn gene clusters are highly homologues in sequence (Fig. 1b and Supplementary Table 3). According to the domain organization of three giant polyketide synthases $(\mathrm{PKSs})^{10}$, we proposed an 18 -membered macrolactone intermediate $\mathbf{3}$ was the PKS product in $\mathbf{1}$ biosynthesis (Fig. 1) 9 . This hypothesis was supported by our recent biosynthetic study that a linear polyketide, a spontaneous hydrolyzed product of $\mathbf{3}$, was obtained from a recombinant strain where all tailoring enzymes were eliminated from the stm gene cluster ${ }^{9}$. In addition, we have characterized $\mathrm{StmD}$ as the bispericyclase that catalyzes the formation of $[6+4]$ and $[4+2]$ adducts, both of which can interconvert to each other through a spontaneous [3,3]-Cope rearrangement (Fig. 1), in the biosynthesis of $\mathbf{1}$ through detailed in vivo gene deletion, in vitro biochemical assay as well as density functional theory (DFT) calculations ${ }^{9}$. However, the following questions remain unanswered: (i) which adduct, $[6+4]$ or $[4+$ 2], is the real biosynthetic intermediate for downstream enzymes, (ii) at which step the $[6+4]$-adduct can fully convert to the $[4+$ $2]$-adduct for remaining steps, and (iii) when the $[4+2]$-adduct is stable.

As 7 shares the same 10/6/6-tricyclic ring system with $\mathbf{1}$, we proposed $[4+2]$-adduct 7 instead of $[6+4]$-adduct 6 is the real intermediate in $\mathbf{1}$ biosynthesis, and the thermodynamically more stable $[6+4]$ adduct 6 is converted into the $[4+2]$ adduct 7 through Cope rearrangement when a downstream enzyme, putatively an enoyl reductase-like enzyme is present to transform the $C=C$ double bond in the $\alpha, \beta$-unsaturated ester group of 7 to the $\mathrm{C}-\mathrm{C}$ single bond and stabilize the ten membered ring (Fig. 1c, path a) ${ }^{11,12}$. To identify the downstream enzymes, we comparatively analyzed the encoded enzymes in stm and ngn gene cluster (Fig. 1b, Supplementary Table 3). Totally, 13 homologous enzymes were identified, five of which have already been experimentally characterized by us and other lab: StmA/NgnA, $\mathrm{StmB} / \mathrm{NgnB}$, and StmC/NgnC as three giant $\mathrm{PKSs}^{1}, \mathrm{StmD} / \mathrm{NgnD}$ as a bispericyclase ${ }^{9}$, and $\mathrm{StmO} / \mathrm{NgnO} 3$ as a dioxygenase that catalyzes the ether-bridge formation ${ }^{13,14}$. In addition, StmF/ NgnF, StmM/NgnM, and StmV/NgnV, which were predicted to

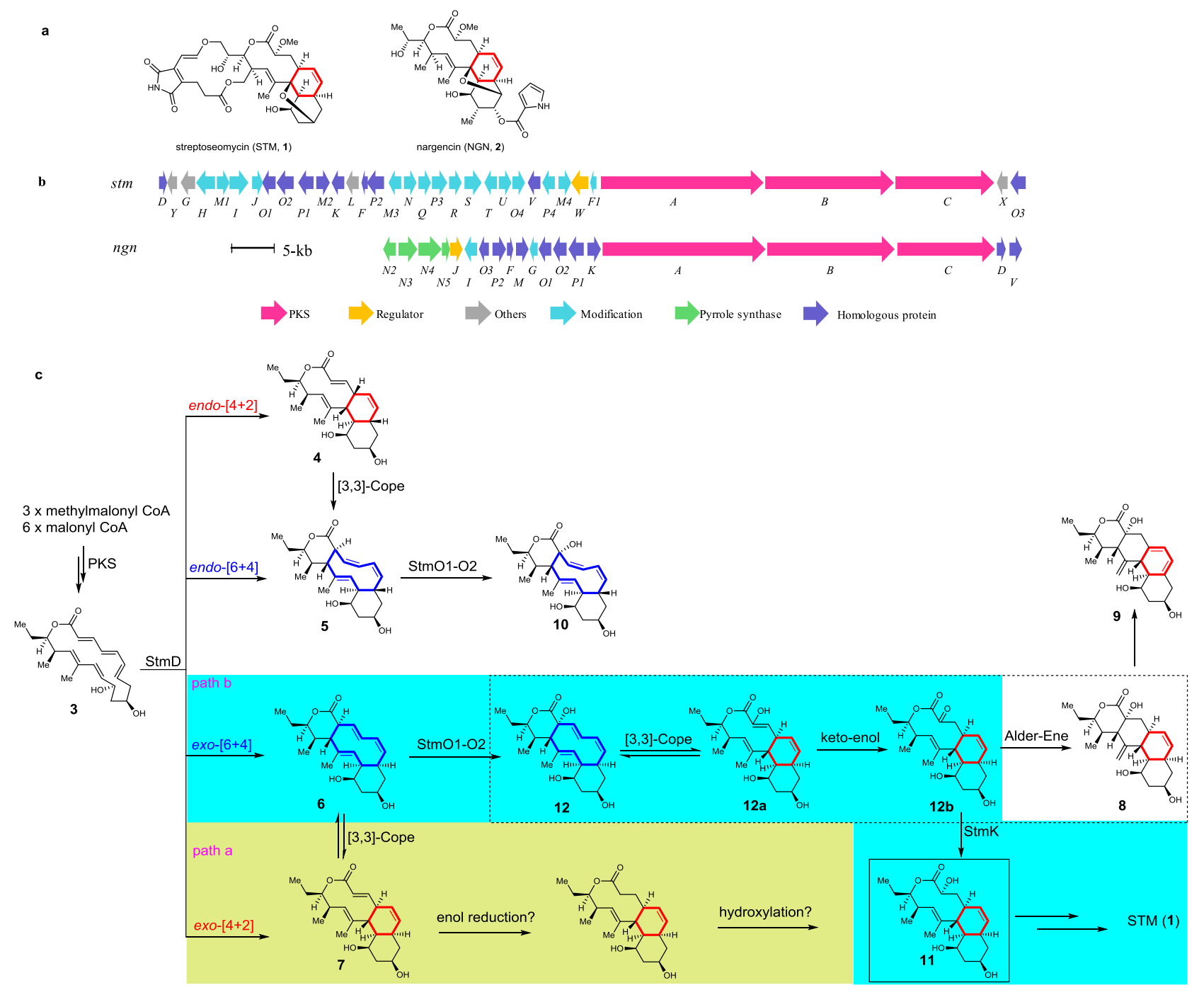

Fig. 1 Biosynthesis of streptoseomycin. a Structures of streptoseomycin (1) and nargenicin (2); b Genetic organization of the stm and ngn gene clusters; c biosynthetic pathway involved in polyketide part of STM biosynthesis. Path a (yellow background) is the original pathway using [4 +2 ]-adduct as the intermediate. Path b (blue background) is the revised pathway starting from $[6+4]$-adduct. Steps in the dashed region are nonenzymatic processes. 


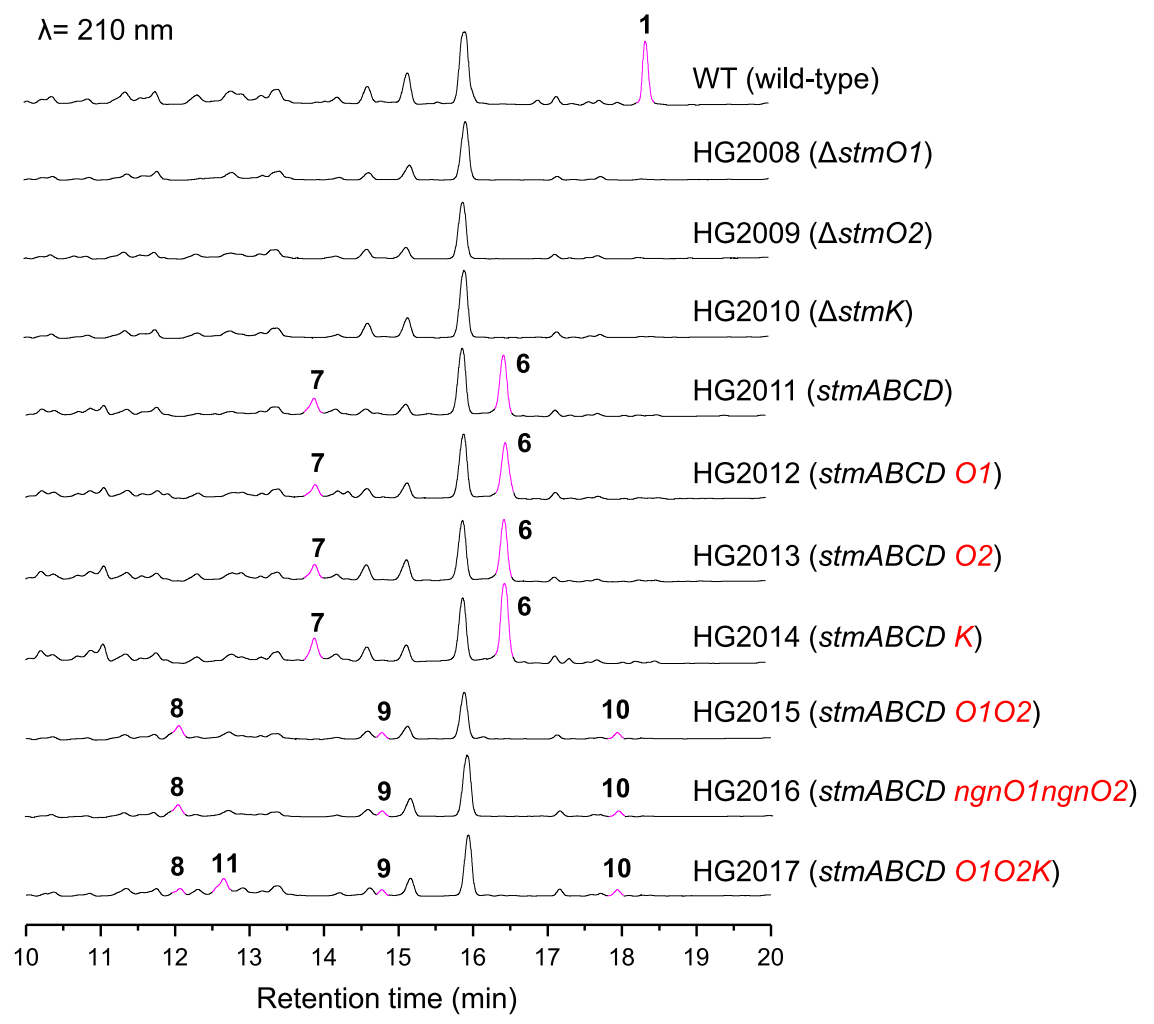

Fig. 2 HPLC analysis of wild-type and recombinant strains. The highlighted peaks were intermediates or shunt metabolites in the stm pathway.

be ferredoxin, methyltransferase and thioesterase, respectively, were unlikely to directly utilize $\mathbf{6}$ or 7 as substrates. The remaining uncharacterized homologous enzymes in $\mathbf{1}$ and $\mathbf{2}$ biosyntheses include two P450 monooxygenases, StmP1/NgnP1 and StmP2/NgnP2, as well as three $\mathrm{NAD}(\mathrm{P}) \mathrm{H}$ or flavindependent oxidoreductases StmO1/NgnO1, StmO2/NgnO2 and StmK/NgnK.

In this work, we report an unusual combination of enzymatic and nonenzymatic cascade installs the 10/6/6-tricyclic core in 1 biosynthesis by the following steps: (i) a pair of flavin-dependent hydroxylases, StmO1-StmO2 complex, hydroxylate C2 in 6 generating a hydroxyl group, (ii) a subsequent spontaneous $[3,3]$ Cope rearrangement followed by an enol-ketone tautomerization forms the 10/6/6-tricyclic core with a C2 ketone group, and (iii) an NADPH-dependent ketoreductase, StmK, reduces the $\mathrm{C} 2$ ketone group affording a stable 10/6/6-tricyclic core; alternatively, ketone-containing intermediate can undergo a nonenzymatic Alder-ene rearrangement forming a 6/6/6/6-tetracyclic shunt metabolite. Moreover, X-ray structure analysis of a pair of StmO1-StmO2 homologous enzymes, NtfO1-NtfO2, reveals protein-protein interactions.

\section{Results and discussion}

StmO1, StmO2, and StmK are essential for STM biosynthesis. As we proposed above, an enoyl reductase-like enzyme was likely required to reduce the $\mathrm{C}=\mathrm{C}$ double bond in the $\alpha, \beta$-unsaturated ester group of 7 using $\mathrm{NAD}(\mathrm{P}) \mathrm{H}$ or reduced flavin as cofactor (Fig. 1c, path a) ${ }^{1,9}$. Thus, we turned our attention on three oxidoreductases, StmO1, StmO2, and StmK. We individually inactivated these three genes through in-frame deletion in $S$. seoulensis A01 wild-type strain, generating HG2008 ( $\Delta$ stmO1),

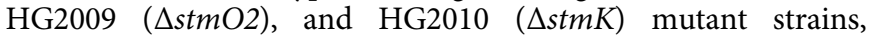
respectively (Supplementary Fig. 1). As expected, all these mutants abolished the production of $\mathbf{1}$ under the fermentation condition described previously ${ }^{9}$, confirming the involvement of these three genes in STM biosynthesis. However, it is strange that no new intermediates including 6 and 7 can be detected from these mutants (Fig. 2) ${ }^{14}$. The production of $\mathbf{1}$ can be restored when gene stmO1, stmO2, or stmK was individually complemented to their corresponding mutants (Supplementary Fig. 2), excluding the possible polar effects of each gene mutation.

StmO1-StmO2 carries out a hydroxylation step. To exclude the possible effects of other tailoring enzymes encoded in the stm gene cluster, we carried out a 'bottom-up' strategy to reconstitute the biosynthetic pathway step by step. First, we removed two remaining putative tailoring enzymes encoding genes stmX and stmO3 in the mutant strain HG2006, where a DNA fragment from $s t m Y$ to $s t m F 1$ were deleted ${ }^{9}$, yielding HG2011 (stmABCD) strain that only harbors three pks genes (stmA, stmB and $\operatorname{stm} C)$ and a bispericyclase gene $(\mathrm{stmD})$ in the stm gene cluster. Under the fermentation condition, HG2011 lost the production of 1 but clearly accumulated exo-[6+4]-adduct (6) and exo-[4+2]adduct (7) as well as a minor endo-[6+4]-adduct (5) (Fig. 2), which was barely detectable. Our previous study has confirmed that $\mathbf{6}$ and 7 were biosynthetic intermediates for $\mathbf{1}$, while $\mathbf{5}$ is an off-pathway metabolite. In addition, in vivo experiments and DFT calculations indicated that $\mathbf{5}$ was formed exclusively in endopathway and the proposed $[4+2]$ adduct 4 does not exist due to its high energy ${ }^{9}$.

Using HG2011 strain as a platform, we set out to evaluate if StmO1, StmO2 or StmK can directly accept and tailor 6 or 7 . Therefore, we cloned these genes individually to the Streptomyces integrative plasmid pSET152 under the control of a strong promoter kasOp*15, and introduced them into HG2011 strain, yielding HG2012 (stmABCDO1), HG2013 (stmABCDO2), and HG2014 (stmABCDK), respectively. However, HPLC analysis indicated none of these recombinant strains could generate any new products (Fig. 2). The partially overlapped coding regions of stmO1 and stmO2 suggest that they are located in the same 


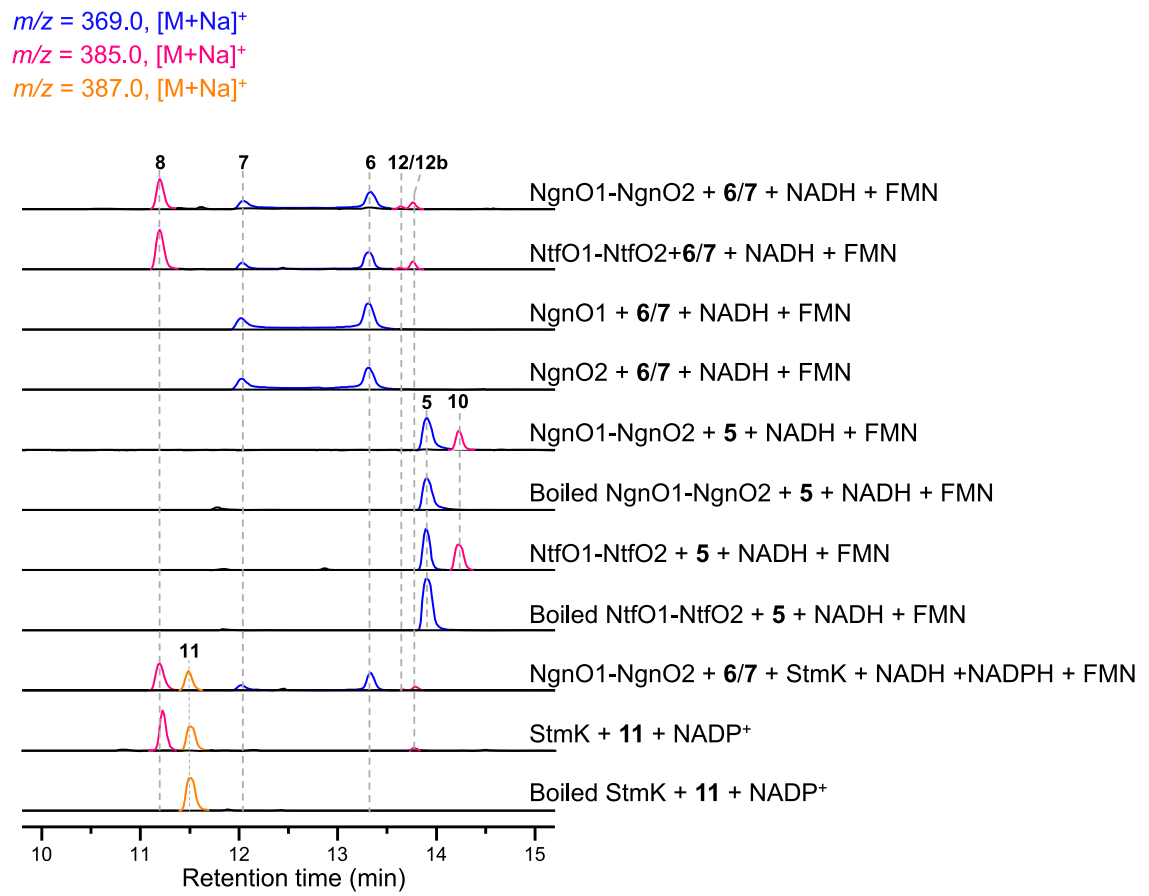

Fig. 3 LC-MS analysis of NgnO1-NgnO2, StmK, and Ntf01-NtfO2 catalyzed reaction. NgnO1-NgnO2 catalyzes a hydroxylation step on 6/7 or 5 when incubated with FMN and NADH; NgnO1 or NgnO2 alone has no effects on 6/7; NtfO1-NtfO2 has the same function with NgnO1-NgnO2; StmK catalyzes a ketoreduction step on the putative intermediate $\mathbf{1 2 b}$; StmK can catalyze a reverse reaction using $\mathbf{1 1}$ as substrate and $\mathrm{NADP}^{+}$as a cofactor.

operon. It is most likely that StmO1 and StmO2 also exist in a complex form. Thus, we cloned stmO1 and stmO2 genes together to pSET152 plasmid under the control of kasOp* promoter and transformed into HG2011, affording HG2015 (stmABCDO1O2) strain. After cultivation, LC-MS analysis of the organic extract showed the appearance of three new peaks, $8(\mathrm{~m} / z 385.2[\mathrm{M}+$ $\left.\mathrm{Na}]^{+}\right), \mathbf{9}\left(\mathrm{m} / z 383.2[\mathrm{M}+\mathrm{Na}]^{+}\right)$and $\mathbf{1 0}\left(\mathrm{m} / z 385.2[\mathrm{M}+\mathrm{Na}]^{+}\right)$ (Fig. 2). A similar HPLC profile was observed when we cointroduced $n g n O 1$ and $n g n O 2$ genes into HG2011 strain (Fig. 2), suggesting StmO1-StmO2 are functionally equivalent to NgnO1-NgnO2. 8-10 were isolated and their structures were elucidated by NMR analysis (Experimental procedures and Supplementary Tables 5-7). While 10 contains an additional hydroxyl group at C-2 compared with 5, both 8 and 9 have an unexpected 6/6/6/6-tetracyclic ring system with an exocyclic alkene (Fig. 1). To test if one of these compounds (8-10) is an onpathway biosynthetic intermediate, we separately fed $\mathbf{8}, \mathbf{9}$, and $\mathbf{1 0}$ to $\triangle$ stmA mutant, a pks deletion strain ${ }^{9}$. LC-MS analysis of metabolic extracts revealed that none of them could restore the production of 1 (Supplementary Fig. 3), indicating 8-10 are not biosynthetic intermediates. Nonetheless, structure analyses for $\mathbf{8}$ 10 imply that (i) StmO1-O2 catalyze an oxidation reaction, (ii) 10 could be the direct hydroxylated product of 5 , (iii) 8 could be a spontaneous rearranged result from a real StmO1-O2 enzymatic product as the stereochemistry of cyclohexene ring in $\mathbf{8}$ is consistent with that of 7 , and (iv) 9 might be an overoxidized product of 8 .

In vivo characterization of StmK as a reductase. Due to our inability to obtain any biosynthetic intermediates from HG2015 strain, we reasoned that the introduction of one more downstream gene into HG2015 strain might catch and convert the labile intermediate to a more stable product. As we analyzed above that the reaction catalyzed by StmO1-StmO2 results in an increase in the oxidation state, a reduction step was still required to generate a proposed intermediate 11 from 6 or 7 . For this purpose, the only remaining $\mathrm{NAD}(\mathrm{P}) \mathrm{H}$-dependent oxidoreductase encoding gene $\operatorname{stm} K$ was cloned into the replicative expression vector pUWL201, placing it under the control of a strong promoter ermEp $* 15$. The resulting construct was conjugated into HG2015 to afford HG2017 (stmABCDO1O2K) ${ }^{16,17}$. LC-MS analysis showed that HG2017 strain could alter the HPLC profile and generate an additional peak $\left(m / z 387.2[\mathrm{M}+\mathrm{Na}]^{+}\right)$ (Fig. 2). A large-scale fermentation of HG2017 strain led to the isolation of $3.6 \mathrm{mg}$ of $\mathbf{1 1}$. Its structure was then determined by analysis of its HRESIMS and NMR data (Experimental procedures, and Supplementary Table 8). Gratifyingly, the structure of 11 is consistent with the proposed biosynthetic intermediate (Fig. 1). Chemical complementation of 11 into $\Delta s t m A$ mutant strain restored the production of $\mathbf{1}$ (Supplementary Fig. 3), confirming 11 is an on-pathway intermediate. Therefore, three redox enzymes, StmO1, StmO2 and StmK, are sufficient to yield the stable 10/6/6-tricyclic intermediate in $\mathbf{1}$ biosynthesis.

With compounds 8-11 in hand, we re-analyze the LC-MS data of the above generated mutant strains. The extracted ion chromatography (EIC) revealed the presence of 5-7 in $\Delta s t m O 1$ and $\Delta s t m O 2$ mutant strains (Supplementary Fig. 4), albeit in low liters; while, ion peaks corresponding to 8-10 were observed in $\Delta s t m K$ strain. These observations are in agreement with functional assignments for StmO1, StmO2, and StmK. The reason that no significant products were generated from mutant strains are probably due to other genes in the gene cluster or the genome may also somehow act on the intermediates. Alternatively, these steps are the key bottleneck steps in the biosynthesis of $1^{14}$. Placing these genes under strong promoters in our 'bottom-up' strategy may boost the metabolic flux, resulting in the increased production of 8-10.

In vitro characterization of NgnO1-NgnO2 as hydroxylase. Given that our in vivo data did not give a clear insight into the conversion from $\mathbf{6 / 7}$ to 11 , we turned to in vitro reconstitution. We cloned and overexpressed stmO1 and stmO2 in E. coli BL21 
a

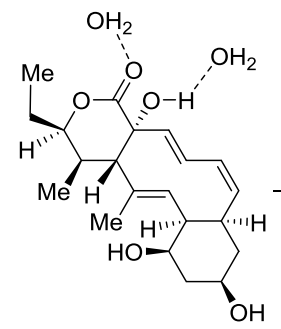

$\begin{array}{cc}\Delta G_{\text {water }} & 12 \\ \left(\mathrm{kcal} \mathrm{mol}^{-1}\right) & (0.0)\end{array}$

$\mathrm{OH}$

$\longrightarrow$

TS-1

(23.5)
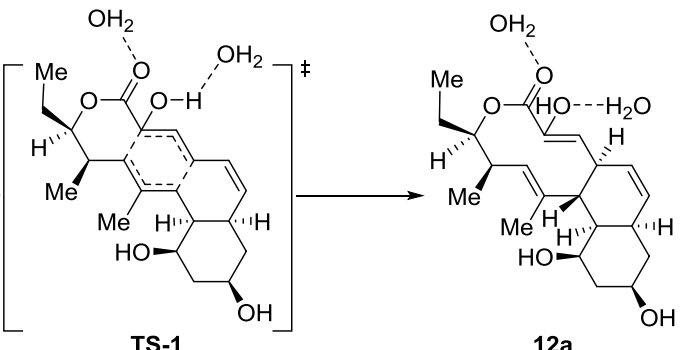

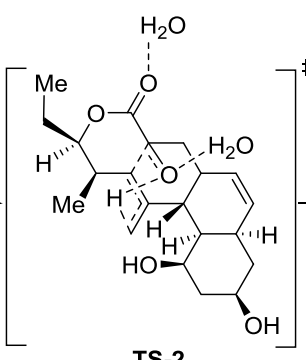

(3.4)

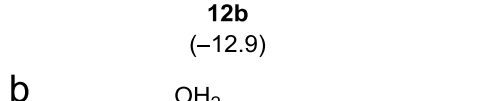

TS-2
$(11.8)$
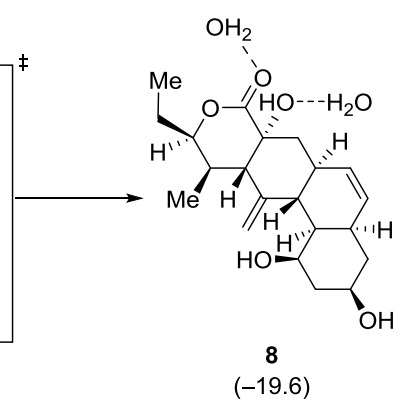

b

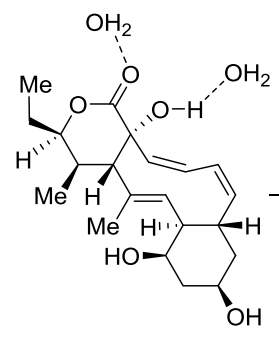

$\begin{array}{cc}\Delta G_{\text {water }} & 10 \\ \left(\mathrm{kcal} \mathrm{mol}^{-1}\right) & (0.0)\end{array}$

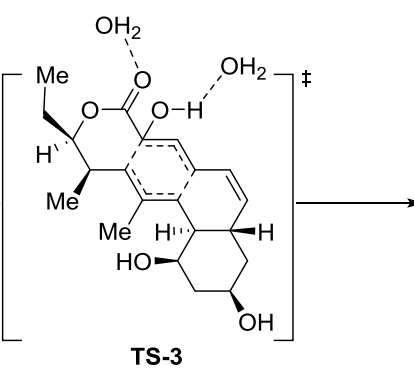

TS-3
(29.6)

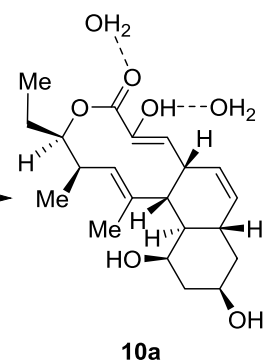

C

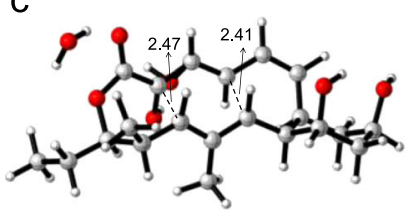

TS-1

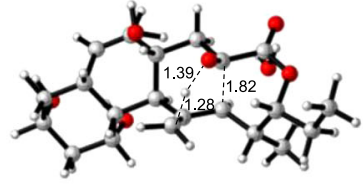

TS-2

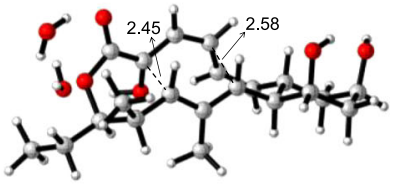

TS-3

Fig. 4 DFT-computed Gibbs free energies. a the Cope rearrangement of $\mathbf{1 2}$ and the subsequent Alder-ene reaction; $\mathbf{b}$ the Cope rearrangement of 10; c transition-state structures (Carbon: gray, Hydrogen: white, Oxygen: red, and distances are shown in $\AA$ ).

(DE3). StmO1 was soluble, while StmO2 was not soluble on its own or when co-expressed with StmO1. After several attempts, we successfully obtained their homologous enzymes NgnO1 and $\mathrm{NgnO} 2$ as soluble proteins (Supplementary Fig. 5) ${ }^{18}$. Incubation of $\mathrm{NgnO} 1$ and $\mathrm{NgnO} 2$ with the substrate mixture of $6 / 7$ in the presence of cofactors NADH and FMN led to the production of 8 (Fig. 3 and Supplementary Fig. 6b). The requirement of cofactors (NADH, NADPH, FAD, and FMN) were systematically investigated. No product can be detected when either $\mathrm{NAD}(\mathrm{P}) \mathrm{H}$ or flavin was omitted from the reaction mixture. NgnO1-NgnO2 prefers to utilize NADH and FMN as a cofactor combination (Supplementary Fig. 7).

Considering that $\mathbf{5}$ and $\mathbf{6}$ have the same planar structure, we then tested if NgnO1-NgnO2 can also accept 5. The NgnO1$\mathrm{NgnO} 2$ assay of $\mathbf{5}$ under the same reaction condition resulted in the production of 10 (Fig. 3 and Supplementary Fig. 6d), clearly indicating that $\mathrm{NgnO} 1-\mathrm{NgnO} 2$ could directly hydroxylate the $s p^{3}$-hybrized carbon C2 of 5 . This result strongly suggested NgnO1-NgnO2 utilized $\mathbf{6}$ instead of $\mathbf{7}$ as substrate, and $\mathbf{1 2}$ is the real product. Similar to the interconversion between 6 and $7^{9}, 12$ can convert to 12a through a spontaneous [3,3]-Cope rearrangement followed by an enol-ketone tautomerization forms the 10/6/6-tricyclic compound $\mathbf{1 2 b}^{7,19,20}$. The enol-ketone tautomerization is the driving force for the Cope rearrangement from 12 to $12 a$. Because we only observed 8 instead of $\mathbf{1 2 b}$ from in vivo and in vitro experiments, therefore a spontaneous Alderene reaction may take place and convert $\mathbf{1 2 b}$ to $\mathbf{8}$ (Fig. 1) 1 (1,22. $^{2}$ The selection of one component in equilibrium with another for biosynthesis is reminiscent of the biosynthesis of phosphonate from PEP, where a homocitrate synthase, FrbC, provides the thermodynamic driving force needed to pull the unfavorable PEP mutase reaction ${ }^{23}$.

DFT calculation for the proposed pathway. To validate the above hypotheses, we performed DFT calculations (Supplementary Data 1). As shown in Fig. 4a, the [3,3]-Cope rearrangement of the predicted C2-hydroxylated intermediate 12 requires an activation free energy of $23.5 \mathrm{kcal} \mathrm{mol}^{-1}$ in water. Such a barrier means that kinetically, this transformation can smoothly occur at room temperature. The generated 10/6/6/-tricyclic enol $12 \mathbf{a}$ is slightly energonic by $3.4 \mathrm{kcal} \mathrm{mol}^{-1}$, but the subsequent tautomerization from 

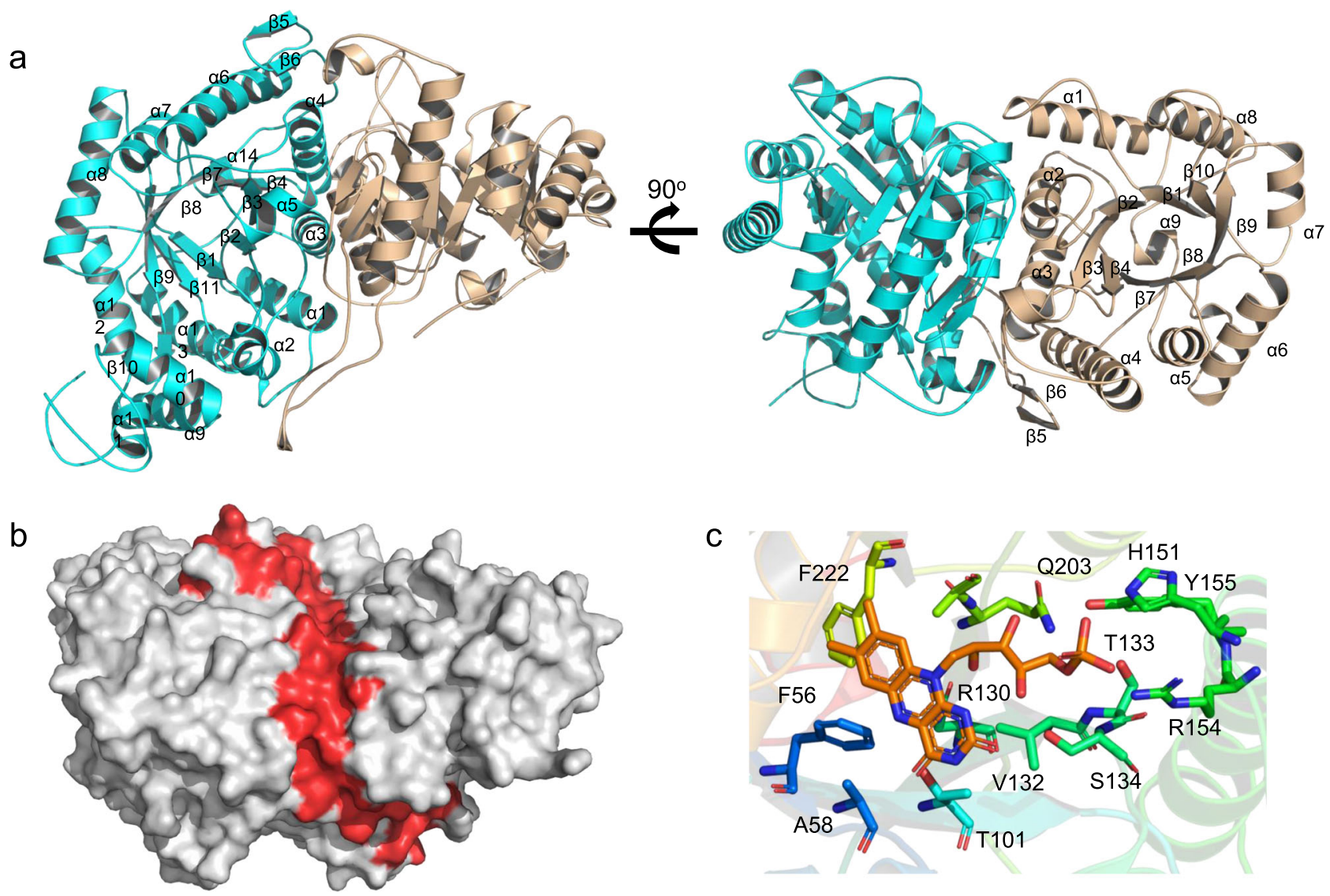

Fig. 5 Crystal structure of NtfO1-NtfO2. a the cartoon structure of $\mathrm{NtfO}$ (wheat) and $\mathrm{NtfO} 2$ (cyan) complex; $\mathbf{b}$ the surface of $01 / \mathrm{O} 2$ complex and the interface was colored red (for more detail see Supplementary Fig. 11); c Key residues of NtfO2, which bind the cofactor, FMN.

enol 12a to ketone $\mathbf{1 2 b}$ dramatically stabilizes the 10/6/6-tricyclic core, since this process is highly exergonic by $16.3 \mathrm{kcal} \mathrm{mol}^{-1}$. Kinetically, the enol-ketone tautomerization can easily occur at room temperature in the presence of water ${ }^{24}$. Further calculations show that the trisubstituted alkene and ketone moieties within the 10 -membered ring of $\mathbf{1 2} \mathbf{b}$ undergo an Alder-ene reaction through transition state TS-2, in which the forming $\mathrm{C}-\mathrm{C}$ and $\mathrm{O}-\mathrm{H}$ bonds are 1.82 and $1.39 \AA$, respectively, and the breaking $\mathrm{C}-\mathrm{H}$ bond is $1.28 \AA$ (Fig. 4c). The computed free energy barrier for this transannular Alder-ene reaction is $24.7 \mathrm{kcal} \mathrm{mol}^{-1}$, just a bit higher than that for the Cope rearrangement of 12 , and the resulting 6/6/6/6tetracyclic product $\mathbf{8}$ is exergonic by $6.7 \mathrm{kcal} \mathrm{mol}^{-1}$. All these computational results support that the conversion of $\mathrm{C} 2$ hydroxylated compound $\mathbf{1 2}$ to the observed product $\mathbf{8}$ can spontaneously take place in water via Cope rearrangement, enol-ketone tautomerization, and Alder-ene reaction. In addition, DFT calculations showed that for the isolated C2-hydroxylated product 10, its [3,3]-Cope rearrangement transition state TS-3 (Fig. 4b) has an activation barrier of $29.6 \mathrm{kcal} \mathrm{mol}^{-1}$, which is about $6 \mathrm{kcal} \mathrm{mol}^{-1}$ higher than that for intermediate 12 (TS-3: $29.6 \mathrm{kcal} \mathrm{mol}^{-1}$ versus TS-1: $23.5 \mathrm{kcal} \mathrm{mol}^{-1}$ ). This indicates that compound $\mathbf{1 0}$ is stable enough in the water at ambient temperature, which is in agreement with the experimental findings.

In vitro characterization of StmK as a ketoreductase. We reasoned that StmK may account for the ketoreduction step of $\mathbf{1 2 b}$ to yield 11. StmK was then overproduced and purified from $E$. coli BL21(DE3) to homogeneity. Because the proposed substrate 12b is not available, we performed a StmK and NgnO1-NgnO2 coupled enzymatic reaction. Upon incubating StmK and NADH into the above $\mathrm{NgnO} 1-\mathrm{NgnO} 2$ reaction system, the production of 11, together with the shunt metabolite $\mathbf{8}$, was observed through LC-MS analysis (Fig. 3).

To further confirm the function of StmK, we carried out a StmK catalyzed reverse reaction using $\mathbf{1 1}$ as substrate. The purified recombinant StmK was incubated with 11 in the presence of excessive $\mathrm{NADP}^{+}$, which led to the formation of $\mathbf{8}$ along with a small ion peak $\left([\mathrm{M}+\mathrm{Na}]^{+}\right.$at 385.1990$)$ corresponding to $\mathrm{C}_{21} \mathrm{H}_{30} \mathrm{O}_{5}$ (Supplementary Fig. 6g), which most likely is $\mathbf{1 2 b}$. Further analysis of EIC spectrum of NgnO1-NgnO2 catalyzed reaction indicated the presence of two minor peaks that could be assigned to $\mathbf{1 2}$ and $\mathbf{1 2 b}$ according to their high-resolution mass data (Fig. 3 and Supplementary Fig. 6b). Though these two compounds cannot be obtained in sufficient amount for structure elucidation, the time-course analysis of $\mathrm{NgnO} 1-\mathrm{NgnO} 2$ biochemical reaction showed the production of these peaks increased at an early time point, and finally converted to the end product (Supplementary Fig. 8), suggesting both compounds are biosynthetic intermediates (Fig. 1c). The DFT calculations indicated 12 and $\mathbf{1 2 b}$ may have a reasonably long half-life for LC-MS detection (Fig. 4). Collectively, these results support the proposed biosynthetic pathway and confirm StmK is a ketoreductase responsible for reducing C2-keto group of $\mathbf{1 2 b}$ to afford $\mathbf{1 1 .}$

Complex structure of NtfO1-NtfO2. Finally, we set out to characterize the structure of NgnO1-NgnO2 for understanding the presumed protein-protein interaction. A highly similar gene cluster ( $n t f)$ of $\mathrm{stm}$ or $n g n$ was identified from Nocardia tenerifensis NBRC 101015 strain (Supplementary Table 4) ${ }^{9}$. Most likely, this gene cluster encodes a nargenicin-like compound. 
Indeed, the recombinant $\mathrm{NtfO} 1-\mathrm{NtfO} 2$ is functionally equivalent to NgnO1-NgnO2, as they also catalyze the same reaction on $\mathbf{5}$ or 6/7 (Fig. 3). Though we failed to get the crystals of NgnO1-NgnO2, the complex of NtfO1-NtfO2 was successfully crystallized in the $\mathrm{P} 12_{1} 1$ space group as a heterodimer in the asymmetric unit with resolution at $2.0 \AA$ (Fig. 5, Supplementary Table 9 and PDB: 7C2R). Consistent with crystal analysis, the quaternary state of NtfO1-NtfO2 complex in solution was determined as a heterodimer by size-exclusion chromatographic analysis (Supplementary Fig. 5). The flat interface area is around $15,120 \AA^{2}$, covering $21.6 \%$ of the total surface. The interface is mainly composed of two sets of $\alpha$-helices, $\alpha 2 / \alpha 3$ from NtfO1 and a3/a4 from NtfO2 (Fig. 5 and Supplementary Fig. 10). Besides polar interactions between $\mathrm{NtfO} 1$ and $\mathrm{NtfO} 2$, like hydrogen bonding network among NtfO2/D32, NtfO1/R156, NtfO2/E78, and $\mathrm{NtfO} 1 / \mathrm{Y} 163$, the predominant interactions are contributed by the hydrophobic residues (Supplementary Fig. 10). Although StmO1, NgnO1, and NtfO1 share relatively low sequence identity in contrast to $\mathrm{StmO} 2, \mathrm{NgnO} 2$, and $\mathrm{NtfO} 2$, amino acid residues located in the interface are highly conserved (Supplementary Figs. 10-12), suggesting StmO1-StmO2 and NgnO1-NgnO2, should also form similar heterodimers.

The overall structures of $\mathrm{NtfO} 1$ and $\mathrm{NtfO} 2$ adopted a typical TIM-barrel with five additional insertions and C-terminus extension to block the barrel, which is a typical structure of luciferase-like monooxygenase family (Supplementary Fig. 13) ${ }^{25-29}$. While NtfO2 possesses the conserved lid over the C-terminal end of the $\beta$-barrel, it lacked a highly conserved side loop tail (Supplementary Fig. 13). Conversely, NtfO1 has the side loop tail and misses the lid (Supplementary Fig. 13). Since the side loop tail is quite conserved and contributes extensive interaction between each subunit in the luciferase-like monooxygenase family, the complementary structure feature of $\mathrm{NtfO} 1$ and $\mathrm{NtfO} 2$ might be the reason why they forge a heterodimer.

In addition, the FMN was docking into the $\mathrm{NtfO} 2$ with -8.2 $\mathrm{kcal} / \mathrm{mol}$ affinity by using structurally similar luciferase-like monooxygenases (1YW1, 5XKD, 3B9O, 6LR5) as templates ${ }^{25,26}$. The phosphate end of FMN was hydrogen bonded to several hydrophilic residues including Q203, Y155, H151, and T133, and the isoalloxazine ring of FMN was laying on the top of the TIM barrel core and surrounded by F222, F56, A58, and T101. To evaluate the putative interaction between key residues and FMN, we carried out site-directed mutagenesis on $\mathrm{NtfO} 2$. The activity of these mutated proteins were analyzed by measuring the formation of 8 by LC-MS analysis. The results showed that H151A, T133A, T101A, and F56A almost completely lost activities compared with wild type (Supplementary Fig. 14). The activities of Y155A and Q203A were decreased by around 80 and $90 \%$, and F222A mutant remains $~ 40 \%$ activity.

In conclusion, we have identified three oxidoreductases StmO1-O2 and StmK that act in tandem to construct the 10/6/ 6-tricyclic skeleton required for STM biosynthesis (Fig. 1, path b). Notably, StmO1-StmO2 hydroxylate [6+4]-adduct $\mathbf{6}$ instead of $[4+2]$-adduct 7 to 12 , which is unexpected. The proposed intermediate 12 undergoes a reversible, nonenzymatic Cope rearrangement to give 12a. To completely shift the equilibrium toward 12a, the reaction has exploited driving force by a subsequent irreversible, nonenzymatic enol-ketone tautomerization. Without the downstream enzyme StmK, 12b can be further converted to $\mathbf{8}$ through a spontaneous Alder-ene reaction. However, with StmK, the off-pathway reaction can be suppressed in favor of a ketoreduction on the C2-carbonyl group. Our work therefore demonstrates an interesting example of how nature creates a combination of enzymatic and nonenzymatic reactions, which are precisely controlled, to synthesize natural products.

\section{Methods}

General experimental procedures. All 1D and 2D NMR experiments were run on a Bruker Avance 600 with a cryoprobe at $600 \mathrm{MHz}$ for ${ }^{1} \mathrm{H}$ and $150 \mathrm{MHz}$ for ${ }^{13} \mathrm{C}$ nuclei or a Bruker Avance III 400 at $400 \mathrm{MHz}$ for ${ }^{1} \mathrm{H}$ and $100 \mathrm{MHz}$ for ${ }^{13} \mathrm{C}$ nuclei. High-resolution LC-MS analysis was performed on an Agilent 6530 TOF LC-MS spectrometer equipped with a Porshell 120 EC-C18 column $(4.5 \times 50 \mathrm{~mm}, 2.7 \mu \mathrm{m}$, Agilent Technologies). Optical rotation values were measured in methanol on a Rudolph Autopol IV automatic polarimeter. UV spectra were recorded on a Nanodrop 2000 spectrometer (Thermo Scientific, USA) with a $10 \mathrm{~mm}$ cuvette. IR spectra were measured on a Nexus870 FT-IR. Semipreparative RP-HPLC was performed on an Agilent 1260 HPLC system with a DAD detector equipped with an Eclipse XDB-C18 column (C-18, $9.4 \times 250 \mathrm{~mm}, 5 \mu \mathrm{m}$, Agilent Technologies). MPLC fractionation was performed on a Biotage Isolera One using a Biotage SNAP Cartridge C18 column (120 g). Recombinant proteins were purified on a GE ÄKTA pure chromatography system with a $5 \mathrm{~mL}$ Histrap HP column (GE Lifesciences).

Bacterial strains, plasmids, culture conditions, and chemicals. The strains and plasmids used in this study are listed in Supplementary Table 1. PCR primers were synthesized by Genscript Biological Technology Co. and listed in Supplementary Table 2. The restriction endonucleases and Phanta Max Super-Fidelity DNA Polymerase were obtained from Thermo Fisher and Vazyme Biotech, respectively. DNA gel extraction and plasmid preparation kits were purchased from Omega BioTek. E. coli strains harboring plasmids were grown in LB (Luria-Bertani medium) with appropriate antibiotics, such as ampicillin $(100 \mu \mathrm{g} / \mathrm{mL})$, apramycin $(50 \mu \mathrm{g} / \mathrm{mL})$, kanamycin $(50 \mu \mathrm{g} / \mathrm{mL})$ or chloramphenicol $(25 \mu \mathrm{g} / \mathrm{mL})^{30}$. E. coli ET12567/pUZ8002 was used as the host for intergeneric conjugation to $S$. seoulensis A01 and mutant strains were cultivated on ISP 4 medium at $28^{\circ} \mathrm{C}$ for sporulation. Biological reagents, chemicals, media, and enzymes were purchased from standard commercial sources unless otherwise indicated.

Gene inactivation and complementation. Double crossover homologous recombination was used for gene (stmX-stmO3, stmO1, stmO2, and stmK) disruption. To construct the plasmid for inactivation of the stmX-stmO3 gene, the upstream and downstream homologous arms were amplified with up-F/R primers and down-F/R primers (Supplementary Table 2) using genomic DNA of S. seoulensis A01 as a template. Both arms were cloned into the HindIII and EcoRI sites of pKC1139 to afford plasmid pHG02034. pHG02034 was then conjugated into $S$. seoulensis A01 following the standard procedure ${ }^{31}$. After cultured for 3 days at $30{ }^{\circ} \mathrm{C}$, the colonies with apramycin resistant were transferred to ISP4 plates supplied with apramycin antibiotics at a final concentration of $50 \mu \mathrm{g} / \mathrm{mL}$. The apramycin-sensitive colonies were picked as candidate for double-crossover mutants. The genotype of $\Delta s t m X$-stmO3 was verified by diagnostic PCR using the primers listed in Supplementary Table 2 and DNA-gel analysis (Supplementary Fig. 1). Inactivation of $s t m O 1$, stmO2, and $s t m K$ were performed using the same method described above.

For gene complementation, the fragment containing stmO1 has ligated to the SpeI and EcoRI sites of pSET152-KasOp* plasmid to produce pHG02038. Then, the plasmid pHG02038 was transformed into HG2008 ( $\Delta$ stmO1) by conjugation to generate strain HG2018, and transformed to HG2011 (stmABCD) to obtain strain HG2012 (stmABCDO1).

Similarly, the pSET152-KasOp* derived plasmid pHG02039 that contained the gene stmO2 was conjugated to HG2009 ( $\triangle$ stmO2) and HG2011 (stmABCD) to afford HG2019 (AstmO2::stmO2) and HG2013 (stmABCDO2), respectively. The pSET152-KasOp* derived plasmid pHG02040 that contained the gene $\operatorname{stmK}$ was conjugated to HG2010 ( $\triangle$ stmK) and HG2011 (stmABCD) to afford HG2020 $(\triangle s t m K:: s t m K)$ and HG2014 (stmABCDK), respectively. The pSET152-KasOp* derived plasmid pHG02041 containing genes stmO1 and stmO2 was transformed to HG2011 (stmABCD) to generate strain HG2015 (stmABCDO1O2). The plasmid pHG02042 containing the gene $n g n O 1$ and $n g n O 2$ was transformed to HG2011 (stmABCD) to generate strain HG2016 (stmABCDngnO1O2). The pUWL201ErmEp* derived plasmid pHG02043 that contained $s t m K$ gene was transferred to the strain HG2015 to generate strain HG2017 (stmABCDO1O2K).

Fermentation and analysis of intermediates. The small-scale fermentations for wild-type and gene recombinant strains were carried out using the same method reported previously ${ }^{1}$. In brief, fresh spores of mutant strains were inoculated into $50 \mathrm{~mL}$ TSB medium at $28^{\circ} \mathrm{C}$ and $200 \mathrm{rpm}$ for two days. The seed culture was then inoculated into a production medium ( $5 \mathrm{~g}$ peptone, $2 \mathrm{~g}$ beef extract, $5 \mathrm{~g}$ glucose, $1.0 \mathrm{~g} \mathrm{~K}_{2} \mathrm{HPO}_{4}, 0.5 \mathrm{~g} \mathrm{FeSO}_{4}$ in $1 \mathrm{~L}$ water, $\mathrm{pH} \mathrm{7.0)}$ at $28^{\circ} \mathrm{C}$ and cultivated for eight days. Then, the supernatant of the fermentation broth was extracted with ethyl acetate and concentrated for LC-MS analysis. LC-MS analysis was performed in a 23 min linear gradient system from 20 to $90 \%(\mathrm{v} / \mathrm{v})$ methanol in water containing $0.1 \%$ formic acid.

Isolation of the intermediates. For compound isolation, a 10-L scale fermentation for (HG2015 and HG2017) was carried out individually. The fermentation broth was filtered and the supernatant was extracted three times with ethyl acetate, then the crude extract was separated by a medium-pressure liquid chromatography (MPLC) system equipped a Biotage SNAP Ultra C18 $120 \mathrm{~g}$ column using a linear 
gradient system from 20 to $90 \%(\mathrm{v} / \mathrm{v})$ methanol/water. The fractions were analyzed by HPLC. Those fractions containing the target compounds were combined and further purified by semi-preparative HPLC. Compound $8\left(8.3 \mathrm{mg}, \mathrm{t}_{R}=21.5 \mathrm{~min}\right)$ was purified from the HG2015 strain by semi-preparative HPLC using $25 \% \mathrm{MeCN}$ in $\mathrm{H}_{2} \mathrm{O}$ at a flow rate of $2 \mathrm{~mL} / \mathrm{min}$. Compound $9\left(7.5 \mathrm{mg}, t_{R}=18.6 \mathrm{~min}\right)$ and compound $10\left(1.5 \mathrm{mg}, t_{R}=25.3 \mathrm{~min}\right)$ were purified from the same strain by semipreparative $\mathrm{HPLC}$ using $25 \% \mathrm{MeCN}$ in $\mathrm{H}_{2} \mathrm{O}$ and $21 \% \mathrm{MeCN}$ in $\mathrm{H}_{2} \mathrm{O}$, respectively, at a flow rate of $2 \mathrm{~mL} / \mathrm{min}$. Compound $11\left(3.6 \mathrm{mg}, t_{R}=27.1 \mathrm{~min}\right)$ was purified from the HG2017 strain by semi-preparative HPLC using $34 \% \mathrm{MeCN}$ in $\mathrm{H}_{2} \mathrm{O}$ at a flow rate of $2 \mathrm{~mL} / \mathrm{min}$.

Structure elucidation for 8-11. The molecular formula of compound $\mathbf{8}$ was determined to be $\mathrm{C}_{21} \mathrm{H}_{30} \mathrm{O}_{5}$ based on its HR-ESIMS analysis (Supplementary Fig. 15) and NMR data (Supplementary Table 5, Supplementary Figs. 16-22), indicating seven degrees of unsaturation. The ${ }^{1} \mathrm{H}$ NMR, ${ }^{13} \mathrm{C} N M R$, and HSQC spectra displayed the presence of one ester carbonyl (C-1), one trisubstituted olefinic carbon (C-14), one terminal olefinic carbon (C-21), two olefinic methines (C-5, C-6), accounting for three out of seven degrees of unsaturation. Therefore, 8 should be a tetracyclic structure. In addition, NMR data revealed the presence of three oxygenated aliphatic methines (C-9, C-11, and C-17), six aliphatic methines (C-4, C-7, C-12, C-13, C-15, and C-16), four aliphatic methylenes (C-3, C-8, C-10, and $\mathrm{C}-18)$, two methyl groups (C-19 and C-20), one oxygenated quaternary carbon $(\mathrm{C}-2)$ and three $\mathrm{D}_{2} \mathrm{O}$ exchangeable signals $\left(\delta_{\mathrm{H}} 3.27,3.69,4.38\right)$ corresponding to three hydroxyl groups. Interpretation of the ${ }^{1} \mathrm{H}-{ }^{1} \mathrm{H}$ COSY spectrum revealed the presence of two distinctive spin systems, $\mathrm{H}-3$ to $\mathrm{H}-13$, and $\mathrm{H}-15$ to $\mathrm{H}-20$. The two spin systems were connected through $\mathrm{HMBC}$ and ${ }^{13} \mathrm{C}$ chemical shift analysis. The presence of one decalin subunit was indicated by ${ }^{1} \mathrm{H}-{ }^{1} \mathrm{H}$ COSY and $\mathrm{HMBC}$ corrections from $\mathrm{H}-3, \mathrm{H}-5$ to $\mathrm{C}-13$, and $\mathrm{H}-6, \mathrm{H}-12$ to $\mathrm{C}-4$. HMBC corrections from $\mathrm{H}-$ $15, \mathrm{H}-17$, and $2-\mathrm{OH}$ to $\mathrm{C}-1$ allowed for the formation of a 6 -membered lactone ring. Another 6-membered ring was established from $\mathrm{H}-21$ to $\mathrm{C}-13, \mathrm{C}-14$, and $\mathrm{C}$ 15 , and from $2-\mathrm{OH}$ to $\mathrm{C}-1, \mathrm{C}-2, \mathrm{C}-3$, and C-15. Thus, the planar structure of 8 was determined. The NOE correlations of $2-\mathrm{OH}$ with $\mathrm{H}-4$, of $\mathrm{H}-17$ with $\mathrm{H}-6$, and of $\mathrm{H}-$ 20 with $\mathrm{H}-15$ established the stereochemistry of C-2, C-15, C-16, and C-17.

The molecular formula of compound 9 was determined to be $\mathrm{C}_{21} \mathrm{H}_{28} \mathrm{O}_{5}$ based on the HR-ESIMS analysis (Supplementary Fig. 23) and NMR data (Supplementary Table 6, Supplementary Figs. 24-30), suggesting that 9 has one more degree of unsaturation than that of $\mathbf{8}$. The NMR data of $\mathbf{9}$ were highly similar to those of $\mathbf{8}$ except for the absence of signals corresponding to aliphatic methine at C-4 and C-7 in 8. Instead, there were two additional $\mathrm{sp}^{2}$-hybridized carbons corresponding to trisubstituted olefinic carbons $\left(\delta_{\mathrm{C}} 133.6\right.$ and 131.7). The above observation suggested that one of the single bond in $\mathbf{8}$ might be desaturated in $\mathbf{9}$, which was in agreement with the molecular mass of 9 . HMBC correlations from $\mathrm{H}-12$ to $\mathrm{C}-4$, from $\mathrm{H}-6$ to $\mathrm{C}-4$ and C-12, and from $\mathrm{H}-5$ to $\mathrm{C}-7$ and C-13 revealed the presence of a cyclohexadiene ring. Further interpretation of 1D and 2D NMR data established the structure of 9 .

The molecular formula of compound $\mathbf{1 0}$ was determined to be $\mathrm{C}_{21} \mathrm{H}_{30} \mathrm{O}_{5}$ according to its HR-ESIMS (Supplementary Fig. 31) and NMR data (Supplementary Table 7, Supplementary Figs. 32-38), indicating 7 degrees of unsaturation. The NMR data of 10 were very similar to those of $5^{9}$, except for the absence of signals corresponding to aliphatic methine at C-2 in 5. Instead, there were additional NMR signals corresponding to an oxygenated quaternary carbon $\left(\delta_{\mathrm{C}} 79.4\right)$ and one hydroxyl proton $\left(2-\mathrm{OH}, \delta_{\mathrm{H}} 4.92\right.$, brs). The HMBC correlations from 2-OH to C-2 and C-3 indicated 10 has an additional 2-hydroxyl group at C-2 position compared with $\mathbf{5}$. Compound 10 showed a similar NOE pattern to that of $5^{9}$. In addition, the NOE correlation of $2-\mathrm{OH}$ with $\mathrm{H}-16$ established the stereochemistry of $\mathrm{C}-2$ as shown in Fig. 1.

The molecular formula of compound $\mathbf{1 1}$ was determined to be $\mathrm{C}_{21} \mathrm{H}_{32} \mathrm{O}_{5}$ based on the HR-ESIMS analysis (Supplementary Fig. 39) and NMR data (Supplementary Table 8, Supplementary Figs. 40-46), indicating six degrees of unsaturation. The ${ }^{1} \mathrm{H}$ NMR, ${ }^{13} \mathrm{C} \mathrm{NMR}$, and HSQC spectra indicated the presence of one ester carbonyl (C-1), three olefinic methines (C-5, C-6, and C-15), one trisubstituted olefinic carbon (C-14), accounting for three out of six degrees of unsaturation. Therefore, 11 is a tricyclic structure. Analysis $1 \mathrm{D}$ and 2D NMR data indicated the presence of four oxygenated aliphatic methines (C-2, C-9, C-11, and C-17), six aliphatic methines (C-4, C-7, C-12, C-13, and C-16), four aliphatic methylenes (C$3, \mathrm{C}-8, \mathrm{C}-10$, and C-18), three methyl groups (C-19, C-20, and C-21). Interpretation of the ${ }^{1} \mathrm{H}^{-1} \mathrm{H}$ COSY spectrum displayed the presence of two distinctive spin systems, $\mathrm{H}-2$ to $\mathrm{H}-13$, and $\mathrm{H}-15$ to $\mathrm{H}-20$. One methyl group (C-21) was attached to $\mathrm{C}-14$ through $\mathrm{HMBC}$ correlations of $\mathrm{H}-21$ to $\mathrm{C}-13, \mathrm{C}-14$, and $\mathrm{C}$ 15. The presence of one decalin subunit was indicated by ${ }^{1} \mathrm{H}-{ }^{1} \mathrm{H}$ COSY and HMBC corrections from $\mathrm{H}-3, \mathrm{H}-5$, and $\mathrm{H}-7$ to $\mathrm{C}-13$ and $\mathrm{H}-6, \mathrm{H}-12$ to $\mathrm{C}-4{ }^{9}$. In addition, the HMBC correlations from $\mathrm{H}-2, \mathrm{H}-3, \mathrm{H}-17$, and $2-\mathrm{OH}$ to $\mathrm{C}-1$ allowed for the formation of a 10-membered lactone ring. Thus, the planar structure of $\mathbf{8}$ was determined. The NOE correlations from $\mathrm{H}-2\left(\delta_{\mathrm{H}} 4.02\right)$ to $\mathrm{H}-3 \beta\left(\delta_{\mathrm{H}} 1.78\right)$, and from $\mathrm{H}-3 \beta\left(\delta_{\mathrm{H}} 1.78\right)$ to $\mathrm{H}-5\left(\delta_{\mathrm{H}} 5.58\right)$ established the stereochemistry of C-2, which was confirmed by our feeding experiment that $\mathbf{1 1}$ is a biosynthetic intermediate in streptoseomycin biosynthesis.

Physicochemical data of 8-11. Compound 8, yellow oil, $[\alpha]_{\mathrm{D}}{ }^{25}-47.5(c 0.16$, $\mathrm{MeOH}) ; \mathrm{UV}(\mathrm{MeOH}): \lambda \max (\log \varepsilon)=208(3.25) \mathrm{nm}$; IR $(\mathrm{KBr}) v_{\max } 3396,3011$,
2968, 2934, 2879, 1725, $1644 \mathrm{~cm}^{-1}$; HR-ESIMS (positive mode): $\mathrm{m} / z$ calcd. for $\mathrm{C}_{21} \mathrm{H}_{30} \mathrm{O}_{5} \mathrm{Na}^{+}:$385.1985, found $385.1991[\mathrm{M}+\mathrm{Na}]^{+} .{ }^{1} \mathrm{H}$ and ${ }^{13} \mathrm{C} \mathrm{NMR}$ data see Supplementary Table 5.

Compound 9, yellow oil, $[a]_{\mathrm{D}}{ }^{25}-177.3$ (c 0.56, MeOH); UV(MeOH): $\lambda \max$ $(\log \varepsilon)=217(3.27) \mathrm{nm}, 270(3.55) \mathrm{nm}, 281(3.59) \mathrm{nm}, 291(3.41) \mathrm{nm}$; IR (KBr) $v_{\max } 3395,3094,2967,2932,2879,1730,1642 \mathrm{~cm}^{-1}$; HR-ESIMS (positive mode) $\mathrm{m} / z$ calcd. for $\mathrm{C}_{21} \mathrm{H}_{28} \mathrm{O}_{5} \mathrm{Na}^{+}: 383.1829$, found $383.1832[\mathrm{M}+\mathrm{Na}]^{+} .{ }^{1} \mathrm{H}$ and ${ }^{13} \mathrm{C}$ NMR data see Supplementary Table 6.

Compound 10, colorless needle, $[\alpha]_{\mathrm{D}}{ }^{25}+45.3(c$ 0.07, MeOH); UV(MeOH): $\lambda \max (\log \varepsilon)=214(3.38) \mathrm{nm}, 228(3.34) \mathrm{nm} ; \mathrm{IR}(\mathrm{KBr}) v_{\max } 3295,2924,2855,1736$, $1710,1599 \mathrm{~cm}^{-1}$; HR-ESIMS (positive mode): $\mathrm{m} / z$ calcd. for $\mathrm{C}_{21} \mathrm{H}_{30} \mathrm{O}_{5} \mathrm{Na}^{+}$: 385.1985, found $385.1993[\mathrm{M}+\mathrm{Na}]{ }^{+} .{ }^{1} \mathrm{H}$ and ${ }^{13} \mathrm{C}$ NMR data see Supplementary Table 7.

Compound 11, white soild, $[\alpha]_{\mathrm{D}}{ }^{25}-16.0$ (c 0.05, MeOH); UV(MeOH): $\lambda \max$ $(\log \varepsilon)=210(3.41) \mathrm{nm} ; \mathrm{IR}(\mathrm{KBr}) v_{\max } 3371,3013,2964,2929,2876,1718,1603 \mathrm{~cm}^{-1}$; HR-ESIMS (positive mode): $\mathrm{m} / z$ calcd. for $\mathrm{C}_{21} \mathrm{H}_{32} \mathrm{O}_{5} \mathrm{Na}^{+}: 387.2142$, found 387.2149 $[\mathrm{M}+\mathrm{Na}]^{+} .{ }^{1} \mathrm{H}$ and ${ }^{13} \mathrm{C}$ NMR data see Supplementary Table 8.

Gene expression and protein purification. The gene stmO1 was amplified by PCR using primers 28a-stmO1-F/R with genomic DNA of S. seoulensis A01 as template. After purification, the fragment was ligated with linearized pET28a(+) (digested by HindIII and NdeI) using the ClonExpress MultiS One Step Cloning Kit (Vazyme Co., Biotech) according to the manufacturer's protocol to generate pHG02044. For gene expression of NgnO1, NgnO2, NtfO1-NtfO2, and StmK, similar procedures were carried out, the fragment of ngnO1, ngnO2, ntfO1-ntfO2, and $s t m K$ was amplified by PCR using the genomic DNA of N. argentinensis ATCC 31306, N. tenerifensis NBRC 101015 and S. seoulensis A01 as template respectively. After purification, the fragments were ligated with linearized pET22b $(+)$ (digested by HindIII and NdeI) except the ngnO1 ligated with linearized pET28a $(+)$, then generate plasmids pHG02045, pHG02046, pHG02047, and pHG02048, respectively.

For gene stmO1 expression, the plasmid pHG02044 was individually transformed into E. coli BL21(DE3), and grown in $400 \mathrm{~mL} \mathrm{LB}$ at $37^{\circ} \mathrm{C}$ with shaking at $220 \mathrm{rpm}$ until an $\mathrm{OD}_{600}$ of $0.4-0.6$ was reached. The culture was cooled to $4{ }^{\circ} \mathrm{C}$ and induced with $0.125 \mathrm{mM}$ IPTG and continued to cultivate at $16^{\circ} \mathrm{C}$ and $220 \mathrm{rpm}$ for $18 \mathrm{~h}$. The cells were harvested by centrifugation at $9000 \times g$ for $10 \mathrm{~min}$. Then the cells were resuspended in $25 \mathrm{~mL}$ lysis buffer $(100 \mathrm{mM}$ Tris, $\mathrm{pH} 8.0,15 \mathrm{mM}$ imidazole, $300 \mathrm{mM} \mathrm{NaCl}, 10 \%$ glycerol) and sonicated at $4{ }^{\circ} \mathrm{C}$. Lysated cell was centrifugated at $18,500 \times \mathrm{g}$ for $30 \mathrm{~min}$ at $4{ }^{\circ} \mathrm{C}$. The supernatant was collected and filtered, then purified by ÄKTA FPLC system using a $5 \mathrm{~mL}$ Histrap HP column (GE lifesciences). The protein was concentrated with an Amicon Ultra-15 $10 \mathrm{kDa}$ spinfilter (EMD Millipore) and desalted by a PD10 column (GE Healthcare) with $100 \mathrm{mM}$ phosphate buffer ( $\mathrm{pH} 7.0$ ) contained $10 \%$ glycerol. The protein was frozen in liquid nitrogen and stored at $-80^{\circ} \mathrm{C}$.

For gene $n g n O 1$ expression, the plasmid pHG02045 was introduced into E. col $\mathrm{BL} 21$ (DE3) and using the similar procedure described in stmO1 expression, we obtained the recombinant NgnO1.

For gene $n g n O 2$ expression, the plasmid pHG02046 was introduced into E. coli BL21(DE3) containing the molecular chaperone plasmid, pGtf2 (Cat. \# 3340; Takara Bio Inc $)^{18,32,33}$. The single transformant was cultivated overnight at $37^{\circ} \mathrm{C}$ in $5 \mathrm{~mL} \mathrm{LB}$ containing ampicillin $(100 \mu \mathrm{g} / \mathrm{mL})$ and chloramphenicol $(25 \mu \mathrm{g} / \mathrm{mL})$. Then, the overnight culture of the recombinant strain was transferred $1 \%$ to $400 \mathrm{~mL}$ LB medium added $100 \mu \mathrm{g} / \mathrm{mL}$ ampicillin, $25 \mu \mathrm{g} / \mathrm{mL}$ chloramphenicol, and $10 \mathrm{ng} / \mathrm{mL}$ tetracyclin (inducing the expression of groES-groEL-tig) cultivated at $37^{\circ} \mathrm{C}$ and $220 \mathrm{rpm}$ until the $\mathrm{OD}_{600}$ value reached 0.6 . The culture was cooled to $4{ }^{\circ} \mathrm{C}$ and induced with $0.125 \mathrm{mM}$ IPTG and continued to cultivate at $16^{\circ} \mathrm{C}$ and $220 \mathrm{rpm}$ for $18 \mathrm{~h}$. The cells were harvested and resuspended in lysis buffer and centrifuged after sonication. The supernatant was filtered and purified by ÄKTA FPLC system equipped with a $5 \mathrm{~mL}$ Histrap HP column (GE Lifesciences). And the protein was desalted and stored at $-80^{\circ} \mathrm{C}$.

For gene NtfO1-NtfO2 expression, the plasmid pHG02047 was introduced into E. coli BL21(DE3). Using the similar procedure described in stmO1 expression, the $\mathrm{NtfO} 1-\mathrm{NtfO} 2$ were obtained as heterodimer.

For gene stmK expression, the plasmid pHG02048 was introduced into E. coli BL21(DE3) containing the chaperone plasmid, pKJE7 (Cat. \# 3340; Takara Bio Inc) ${ }^{18,32,33}$. Using the similar procedure described in $n g n \mathrm{O} 2$ expression, we obtained the recombinant StmK.

The concentration of protein was determined from the absorbance at $280 \mathrm{~nm}$ using a molar absorptivity constant calculated by the ExPASy/ProtParam tool (https://web.expasy.org/protparam/).

In vitro assay of NgnO1, NgnO2, NgnO1-NgnO2. The NgnO1, NgnO2 or NgnO1-NgnO2 catalyzed reaction was carried out in a $100 \mu \mathrm{L}$ reaction system containing $50 \mathrm{mM}$ MES buffer ( $\mathrm{pH}$ 6.7), $200 \mu \mathrm{M}$ substrate, $1 \mathrm{mM}$ NADH, $2 \mu \mathrm{M}$ FMN, $2 \mu \mathrm{M}$ NgnO1 or $2 \mu \mathrm{M}$ NgnO2 or $2 \mu \mathrm{M}$ NgnO1 and $2 \mu \mathrm{M} \mathrm{NgnO} 2$. After incubation at $30^{\circ} \mathrm{C}$ for $3 \mathrm{~h}, 100 \mu \mathrm{L}$ acetonitrile was added to quench the reaction. Then, the reaction mixture was centrifuged at $18,500 \times g$ for $10 \mathrm{~min}$, and the supernatant was subjected to LC-MS analysis. The LC-MS analysis was performed with an $18 \mathrm{~min}$ gradient elution system from 10 to $90 \%$ (1-13 min), $100 \%$ 
(13-15 min), and $10 \%(15-18 \mathrm{~min})$ methanol in water supplied with $0.1 \%$ formic acid at a flow rate of $0.5 \mathrm{~mL} / \mathrm{min}$.

In vitro assay of NtfO1-NtfO2. The $\mathrm{NtfO} 1-\mathrm{NtfO} 2$ catalyzed reaction was carried out in a $100 \mu \mathrm{L}$ reaction system containing $50 \mathrm{mM}$ MES buffer ( $\mathrm{pH}$ 6.7), $200 \mu \mathrm{M}$ substrate, $1 \mathrm{mM}$ NADH, $2 \mu \mathrm{M}$ FMN, $2 \mu \mathrm{M}$ NtfO1-NtfO2. After incubation at $30{ }^{\circ} \mathrm{C}$ for $3 \mathrm{~h}, 100 \mu \mathrm{L}$ acetonitrile was added to quench the reaction. Then, the reaction mixture was centrifuged at $18,500 \times g$ for $10 \mathrm{~min}$, and the supernatant was subjected to LC-MS analysis. The LC-MS analysis was performed with an $18 \mathrm{~min}$ gradient elution system from 10 to $90 \%(1-13 \mathrm{~min}), 100 \%(13-15 \mathrm{~min})$ and $10 \%$ (15-18 $\mathrm{min})$ methanol in water supplied with $0.1 \%$ formic acid at a flow rate of 0.5 $\mathrm{mL} / \mathrm{min}$.

In vitro assay of StmK. The StmK catalyzed reaction was carried out in a $100 \mu \mathrm{L}$ reaction system containing $50 \mathrm{mM}$ PIPES buffer ( $\mathrm{pH}$ 7.1), $200 \mu \mathrm{M}$ substrate, $1 \mathrm{mM}$ NADH, 1 mM NADPH, $20 \mu \mathrm{M}$ FMN, $100 \mathrm{mM} \mathrm{NaCl}, 10 \mathrm{mM} \mathrm{KCl}, 2 \mu \mathrm{M}$ NgnO1, $2 \mu \mathrm{M}$ NgnO2 and $80 \mu \mathrm{M}$ StmK. After incubation at $30^{\circ} \mathrm{C}$ for $4 \mathrm{~h}, 100 \mu \mathrm{L}$ acetonitrile was added to quench the reaction, and then centrifuged at $18,500 \times g$ for $10 \mathrm{~min}$. The supernatant was subjected to LC-MS analysis. The LC-MS analysis was performed with an $18 \mathrm{~min}$ gradient elution system from 10 to $90 \%$ (1-13 min), $100 \%(13-15 \mathrm{~min})$, and $10 \%(15-18 \mathrm{~min})$ methanol in water supplied with $0.1 \%$ formic acid at a flow rate of $0.5 \mathrm{~mL} / \mathrm{min}$.

In vitro assay of StmK-catalyzed reverse reaction. The reverse-reaction of StmK was carried out in a $100 \mu \mathrm{L}$ system containing $50 \mathrm{mM}$ PIPES buffer (pH 7.1), $100 \mu \mathrm{M}$ compound 11 as substrate, $2 \mathrm{mM} \mathrm{NADP}^{+}, 100 \mathrm{mM} \mathrm{NaCl}, 10 \mathrm{mM} \mathrm{KCl}$ and $40 \mu \mathrm{M}$ StmK. After incubation at $30^{\circ} \mathrm{C}$ for about $2 \mathrm{~h}, 100 \mu \mathrm{L}$ acetonitrile was added to quench the reaction, and then centrifuged at $18,500 \times g$ for $10 \mathrm{~min}$. The supernatant was subjected to LC-MS analysis. The LC-MS analysis was performed with an $18 \mathrm{~min}$ gradient elution system from 10 to $90 \%$ (1-13 $\mathrm{min}$ ), $100 \%(13-15 \mathrm{~min})$ and $10 \%(15-18 \mathrm{~min})$ methanol in water supplied with $0.1 \%$ formic acid at a flow rate of $0.5 \mathrm{~mL} / \mathrm{min}$.

Analytical size-exclusion chromatography. The molecular weights (MW) and quaternary state of $\mathrm{NtfO} 1$ and $\mathrm{NtfO} 2$ complex in solution were determined by sizeexclusion chromatography using a Superose 6 Increase 10/300 GL column (GE Healthcare LifeSciences) connected to an ÄKTA Express system (GE Healthcare LifeSciences). The column was pre-equilibrated with two column volumes of $50 \mathrm{mM}$ MES buffer, $\mathrm{pH} 6.7$, and calibrated with ribonuclease A $(13.7 \mathrm{kDa})$, ovalbumin $(44 \mathrm{kDa})$, conalbumin $(75 \mathrm{kDa}), \operatorname{IgG}(150 \mathrm{kDa})$, and ferritin $(440 \mathrm{kDa})$. The chromatography was carried out at $4{ }^{\circ} \mathrm{C}$ at a flow rate of $0.3 \mathrm{~mL} \mathrm{~min}^{-1}$. The column void volume was determined by using Blue Dextran as standard. The calibration curve of $K_{\mathrm{av}}$ versus $\log (\mathrm{MW})$ was prepared using Eq. 1

$$
K_{\mathrm{av}}=\left(V_{\mathrm{e}}-V_{\mathrm{o}}\right) /\left(V_{\mathrm{t}}-V_{\mathrm{o}}\right)
$$

where $V_{\mathrm{e}}, V_{\mathrm{o}}$, and $V_{\mathrm{t}}$ is the elution volume, column void volume, and total bed volume, respectively.

Computational details. The DFT calculations were performed with the Gaussian 09 program package ${ }^{34}$. The geometry optimizations of minima and transition states involved (with two or one explicit water molecule or without water, Fig. 4 and Supplementary Fig. 9) were carried out at the B3LYP-D3 level of theory ${ }^{35}$ with the 6-31 G(d) basis set. The vibrational frequencies were computed at the same level to check whether each optimized structure is an energy minimum or a transition state and to evaluate its zero-point vibration energy (ZPVE) and thermal corrections at 298 K. Solvation energies were computed at the M06-2X level of theory ${ }^{36,37}$ with the $6-311+G(d, p)$ basis set using the gas-phase optimized structures and the CPCM model ${ }^{38-40}$ in water.

Protein crystallization, structural elucidation, and docking study. Crystals were grown at $22{ }^{\circ} \mathrm{C}$ with the sitting-drop vapor-diffusion method. $1 \mu \mathrm{L}$ drop consisted of $1: 1$ ratio of proteins $(10 \mathrm{mg} / \mathrm{mL}, 50 \mathrm{mM} \mathrm{NaCl}, 20 \mathrm{mM}$ Tris, $\mathrm{pH} 8.0)$ and crystallization buffer (1.6 M magnesium sulfate, $0.1 \mathrm{M}$ MES monohydrate $\mathrm{pH} 6.5$ ). Crystals of $\mathrm{NtfO} 1$ and $\mathrm{NtfO} 2$ complex were briefly soaked in the crystallization buffer containing additional $15 \%$ glycerol before flash-freezing for protection.

A single-wavelength anomalous diffraction data of the $\mathrm{NtfO} 1$ and $\mathrm{NtfO} 2$ complex was collected at BL17U1 beamline at the Shanghai Synchrotron Radiation Facility (SSRF) at wavelengths of $0.97918 \AA^{41}$. The diffraction datasets were processed and scaled using imosflm ${ }^{42}$. The phase problem of the complex was solved by the molecular replacement method using the structure of the YTNJ protein (PDB ID: 1TVL) as the search model with PHASER ${ }^{43}$ and further autobuilded and refined by PHENIX $^{44}$, COOT was used for manually model rebuilding and adjustments ${ }^{45}$. Finally, additional TLS refinement was performed in PHENIX. The final refinement statistics are listed in Supplementary Table 9. Structural diagrams were prepared using the program PyMOL (http://www.pymol.org/). The FMN was docked into the putative binding pocket by using Autodock Vina ${ }^{46}$.
Site-directed mutagenesis of NtfO2. Mutated fragments were amplified with primers listed in Supplementary Table 2 by using plasmid pHG02047 as template. The purified PCR products were incubated with DpnI, T4 polynucleotide kinase, and T4 DNA ligase, according to the standard procedure of Q $5^{\oplus}$ Site-Directed Mutagenesis Kit purchased from NEB (USA). Each mutation was confirmed by sequencing. The recombined plasmids were expressed in E. coli BL21(DE3) and purified as described above for native protein.

Reporting summary. Further information on research design is available in the Nature Research Reporting Summary linked to this article.

\section{Data availability}

Data supporting the findings of this work are available within the paper and its Supplementary Information files. A reporting summary for this Article is available as a Supplementary Information file. All additional data supporting the current study in the article or its Supplementary Information files are available from the corresponding author upon request. Atomic coordinates of $\mathrm{NtfO} 1-\mathrm{NtfO} 2$ have been deposited in the Protein Data Bank (PDB) with accession codes 7E36 Data of the sequences supporting this work have been deposited in Genbank with accession codes MG891745 for streptoseomycin gene cluster and MH544245 for nargenicin gene cluster. The source data underlying Supplementary Figs. 5f, 7, and 14 are provided as a Source Data file. Source data are provided with this paper.

Received: 10 November 2020; Accepted: 10 March 2021; Published online: 07 April 2021

\section{References}

1. Zhang, B. et al. Discovery, biosynthesis, and heterologous production of streptoseomycin, an anti-microaerophilic bacteria macrodilactone. Org. Lett. 20, 2967-2971 (2018).

2. Cane, D. E. \& Luo, G. Biosynthesis of polyketide antibiotics. Incorporation of a pentaketide chain elongation. J. Am. Chem. Soc. 117, 6633-6634 (1995).

3. Whaley, H. A., Chidester, C. G., Mizsak, S. A. \& Wnuk, R. J. Nodusmicin: the structure of a new antibiotic. Tetrahedron Lett. 21, 3659-3662 (1980).

4. Rasmussen, R. R. et al. Coloradocin, an antibiotic from a new Actinoplanes. II. Identity with luminamicin and elucidation of structure. J. Antibiot. 40, 1383-1393 (1987)

5. Gouda, H. et al. Stereostructure of luminamicin, an anaerobic antibiotic, via molecular dynamics, NMR spectroscopy, and the modified Mosher method. Proc. Natl Acad. Sci. USA 102, 18286-18291 (2005).

6. Cikos, A. et al. Reinvestigation of the branimycin stereochemistry at position 17-c. Org. Lett. 18, 780-783 (2016).

7. Brana, A. F. et al. Branimycins B and C, antibiotics produced by the abyssal Actinobacterium Pseudonocardia carboxydivorans M-227. J. Nat. Prod. 80, 569-573 (2017).

8. Satoshi, O. et al. Luminamicin, a new antibiotic production, isolation and physico-chemical and biological properties. J. Antibiot. 38, 1322-1326 (1985)

9. Zhang, B. et al. Enzyme-catalysed $[6+4]$ cycloadditions in the biosynthesis of natural products. Nature 568, 122-126 (2019).

10. Keatinge-Clay, A. T. The structures of type I polyketide synthases. Nat. Prod. Rep. 29, 1050-1073 (2012).

11. Keatinge-Clay, A. T. The uncommon enzymology of cis-acyltransferase assembly lines. Chem. Rev. 117, 5334-5366 (2017).

12. Tang, M. C., Zou, Y., Watanabe, K., Walsh, C. T. \& Tang, Y. Oxidative cyclization in natural product biosynthesis. Chem. Rev. 117, 5226-5333 (2017).

13. Pidot, S. J. et al. Biosynthesis and ether-bridge formation in nargenicin macrolides. Angew. Chem. Int. Ed. 58, 3996-4001 (2019).

14. Dhakal, D. et al. Characterization of tailoring steps of nargenicin Al biosynthesis reveals a novel analogue with anticancer activities. ACS Chem. Biol. 15, 1370-1380 (2020).

15. W, W. S. et al. An engineered strong promoter for Streptomycetes. Appl. Environ. Microbiol. 79, 4484-4492 (2013).

16. Kim, T. et al. Novel aldo-keto reductases for the biocatalytic conversion of 3 hydroxybutanal to 1,3-butanediol: structural and biochemical studies. Appl. Environ. Microbiol. 83, e03172-16 (2017).

17. Penning, T. M. The aldo-keto reductases (AKRs): overview. Chem. Biol. Interact. 234, 236-246 (2015).

18. Thomas, J. G., Ayling, A. \& Baneyx, F. Molecular chaperones, folding catalysts, and the recovery of active recombinant proteins from E. coli. Appl. Biochem. Biotech. 66, 197-238 (1997).

19. So, S. M., Mui, L., Kim, H. \& Chin, J. Understanding the interplay of weak forces in [3,3]-sigmatropic rearrangement for stereospecific synthesis of diamines. Acc. Chem. Res. 45, 1345-1355 (2012). 
20. Gao, S. S. et al. Phenalenone polyketide cyclization catalyzed by fungal polyketide synthase and flavin-dependent monooxygenase. J. Am. Chem. Soc. 138, 4249-4259 (2016).

21. Hooper, J., Sauer, E. L., Arns, S., Woo, T. K. \& Barriault, L. On the origin of altered diastereomeric ratios for anionic versus neutral reaction conditions in the oxy-Cope/ene reaction: an interplay of experiment and computational modeling. Chem. Eur. J. 16, 14124-14130 (2010)

22. Rajapaksa, N. S. \& Jacobsen, E. N. Enantioselective catalytic transannular ketone-ene reactions. Org. Lett. 15, 4238-4241 (2013).

23. Metcalf, W. W. \& van der Donk, W. A. Biosynthesis of phosphonic and phosphinic acid natural products. Annu. Rev. Biochem. 78, 65-94 (2009).

24. Liang, Y., Zhou, H. \& Yu, Z. X. Why is copper(I) complex more competent than dirhodium(II) complex in catalytic asymmetric $\mathrm{O}-\mathrm{H}$ insertion reactions? A computational study of the metal carbenoid $\mathrm{O}-\mathrm{H}$ insertion into water. $J$. Am. Chem. Soc. 131, 17783-17785 (2009).

25. $\mathrm{Li}, \mathrm{L}$. et al. Crystal structure of long-chain alkane monooxygenase (LadA) in complex with coenzyme FMN: unveiling the long-chain alkane hydroxylase. J. Mol. Biol. 376, 453-465 (2008).

26. Jun, S. Y., Lewis, K. M., Youn, B., Xun, L. \& Kang, C. Structural and biochemical characterization of EDTA monooxygenase and its physical interaction with a partner flavin reductase. Mol. Microbiol. 100, 989-1003 (2016).

27. $\mathrm{Su}, \mathrm{T}$. et al. Structural and biochemical characterization of BdsA from Bacillus subtilis WU-S2B, a key enzyme in the " 4 " desulfurization pathway. Front. Microbiol. 9, 231 (2018).

28. Cao, H. Y. et al. Crystal structure of the dimethylsulfide monooxygenase DmoA from Hyphomicrobium sulfonivorans. Acta Crystallogr. F. 74, 781-786 (2018).

29. Okai, M. et al. Crystal structure of dibenzothiophene sulfone monooxygenase BdsA from Bacillus subtilis WU-S2B. Proteins 85, 1171-1177 (2017).

30. Sambrook, J. \& Russell, D. W. Molecular Cloning: A Laboratory Manual (3rd end.); (Cold Spring Harbor Laboratory Press, 2001).

31. Bierman, M. et al. Practical Streptomyces Genetics (The John Innes Foundation, 2000).

32. Nishihara, K., Kanemori, M., Kitagawa, M., Yanagi, H. \& Yura, T. Chaperone coexpression plasmids: differential and synergistic roles of DnaK-DnaJ-GrpE and GroEL-GroES in assisting folding of an allergen of Japanese Cedar Pollen, Cryj2, in Escherichia Coli. Appl. Environ. Microbiol. 64, 1694-1699 (1998).

33. Nishihara, K., Kanemori, M., Yanagi, H. \& Yura, T. Overexpression of trigger factor prevents aggregation of recombinant proteins in Escherichia coli. Appl. Environ. Microbiol. 66, 884-889 (2000).

34. Frisch, M. J. et al. Gaussian 09, revision D.01; (Gaussian Inc., 2013).

35. Grimme, S., Antony, J., Ehrlich, S. \& Krieg, H. A consistent and accurate ab initio parametrization of density functional dispersion correction (DFT-D) for the 94 elements H-Pu. J. Chem. Phys. 132, 154104-154123 (2010).

36. Zhao, Y. \& Truhlar, D. G. The M06 suite of density functionals for main group thermochemistry, thermochemical kinetics, noncovalent interactions, excited states, and transition elements: two new functionals and systematic testing of four M06-class functionals and 12 other functionals. Chem. Acc. 120, 215-241 (2008).

37. Zhao, Y. \& Truhlar, D. G. Density functionals with broad applicability in chemistry. Acc. Chem. Res. 41, 157-167 (2008).

38. Barone, V. \& Cossi, M. Quantum calculation of molecular energies and energy gradients in solution by a conductor solvent model. J. Phys. Chem. A 102, 1995-2001 (1998).

39. Cossi, M., Rega, N., Scalmani, G. \& Barone, V. Energies, structures, and electronic properties of molecules in solution with the C-PCM solvation model. J. Comput. Chem. 24, 669-681 (2003).

40. Takano, Y. \& Houk, K. N. Benchmarking the conductor-like polarizable continuum model (CPCM) for aqueous solvation free energies of neutral and ionic organic molecules. J. Chem. Theory Comput. 1, 70-77 (2005).

41. Wang, Q. S. et al. Upgrade of macromolecular crystallography beamline BL17U1 at SSRF. Nucl. Sci. Tech. 29, 68 (2018).

42. Battye, T. G. G., Kontogiannis, L., Johnson, O., Powell, H. R. \& Leslie, A. G. W. iMOSFLM: a new graphical interface for diffraction-image processing with MOSFLM. Acta Crystallogr. D. 67, 271-281 (2011).
43. McCoy, A. J. et al. Phaser crystallographic software. Appl. Crystallogr. 40, 658-674 (2007).

44. Adams, P. D., Mustyakimov, M., Afonine, P. V. \& Langan, P. Generalized Xray and neutron crystallographic analysis: more accurate and complete structures for biological macromolecules. Acta Crystallogr. D 65, 567-573 (2009).

45. Emsley, P. \& Crispin, M. Structural analysis of glycoproteins: building Nlinked glycans with Coot. Acta Crystallogr. D 74, 256-263 (2018).

46. Trott, O. \& Olson, A. J. AutoDock Vina: improving the speed and accuracy of docking with a new scoring function, efficient optimization, and multithreading. J. Comput. Chem. 31, 455-461 (2010).

\section{Acknowledgements}

This work was financially supported by MOST (2018YFC1706205, 2018YFA0902000, and 2019YFC0312500), NSFC (81925033, 21861142005, 21803030, 81773591, 81673333, 81803380, 81991522, 81991524, and 2171101213), and the Fundamental Research Funds for the Central Universities (14380092, 14380113, and 143801389), and the Jiangsu Innovation \& Entrepreneurship Talents Plan. The authors thank the staff at the beam lines BL17U1 and BL18U1 of Shanghai Synchrotron Radiation Facility (SSRF) for their supports, and the High-Performance Computing Center (HPCC) of Nanjing University for doing the numerical calculations in this paper on its blade cluster system.

\section{Author contributions}

H.M.G. conceived the project; K.B.W., W.W., and H.M.G. designed the experiments K.B.W. and W.W. performed the experiments; B.Z. carried out the protein crystallographic studies. K.B.W., W.W., B.Z., H.J.Z., R.X.T., and H.M.G. analysed the data; X.W., Y.C., and Y.L. conducted the computational studies; and K.B.W., W.W., B.Z., Y.L., and H.M.G. wrote the manuscript. K.B.W., W.W., and B.Z. contributed equally to this work.

\section{Competing interests}

The authors declare no competing interests.

\section{Additional information}

Supplementary information The online version contains supplementary material available at https://doi.org/10.1038/s41467-021-22395-7.

Correspondence and requests for materials should be addressed to Y.L., R.X.T. or H.M.G.

Peer review information Nature Communications thanks the anonymous reviewers for their contributions to the peer review of this work. Peer review reports are available.

Reprints and permission information is available at http://www.nature.com/reprints

Publisher's note Springer Nature remains neutral with regard to jurisdictional claims in published maps and institutional affiliations.

Open Access This article is licensed under a Creative Commons Attribution 4.0 International License, which permits use, sharing, adaptation, distribution and reproduction in any medium or format, as long as you give appropriate credit to the original author(s) and the source, provide a link to the Creative Commons license, and indicate if changes were made. The images or other third party material in this article are included in the article's Creative Commons license, unless indicated otherwise in a credit line to the material. If material is not included in the article's Creative Commons license and your intended use is not permitted by statutory regulation or exceeds the permitted use, you will need to obtain permission directly from the copyright holder. To view a copy of this license, visit http://creativecommons.org/ licenses/by/4.0/

(C) The Author(s) 2021 